\title{
Children with Autism in the Inclusive Preschool Classroom: A Systematic Review of Single-Subject Design Interventions on Social Communication Skills
}

\author{
Sarah G. Hansen • Allison W. Blakely • Jill K. Dolata • \\ Tracy Raulston • Wendy Machalicek
}

Received: 13 May 2014 / Accepted: 17 May 2014 /Published online: 30 May 2014

(C) Springer Science+Business Media New York 2014

\begin{abstract}
Changes in legislation have led to an increased push for children with autism spectrum disorder to be educated in classrooms with typically developing peers. This systematic review of the literature between the years of 2005 and 2012 aimed to identify effective interventions to support the children with autism spectrum disorder in the inclusive preschool classroom. Single-subject studies concerning the improvement of social communication skills for children with autism spectrum disorder in inclusive preschools were identified through systematic searches of electronic databases using key terms, journal hand searches, and ancestral searches of identified articles. Data were extracted from the resulting 16 articles to (a) examine rigor of design, (b) evaluate intervention effectiveness using visual analysis and percentage nonoverlapping data (PND), and (c) determine evidence-based practices. Results suggest a range of effective interventions to improve the social communication skills for children with autism spectrum disorder in inclusive preschool classrooms. Suggestions for future research are discussed.
\end{abstract}

Keywords Autism spectrum disorder · Inclusion ·

Meta-analysis $\cdot$ Preschool $\cdot$ Social skills

\section{Introduction}

Participation in quality early childhood education has direct, positive effects on academic and social outcomes for young children (Camilli and Barnett 2010). Typically developing

S. G. Hansen · A. W. Blakely · J. K. Dolata • T. Raulston •

W. Machalicek $(\bowtie)$

Department of Special Education and Clinical Sciences, Center on

Human Development, University of Oregon, 901 E. 18th Avenue,

Eugene, OR 97403, USA

e-mail:wmachali@uoregon.edu children benefit from early social interaction with peers and play is foundational for many school-aged skills, including social-communication (McClelland and Morrison 2003; Odom et al. 2006). For children with disabilities, participation in early childhood programs that feature education among typically developing peers may provide unique access to these benefits (Guralnick et al. 1996; Ferraioli and Harris 2011). Despite the continued debate about the potential impact of inclusive settings on child outcomes (e.g., Garrick et al. 2000; Killoran et al. 2013), the early childhood experience has changed for children with disabilities with an increasing trend for young children with disabilities to be educated alongside typically developing peers whenever possible (Boyle et al. 2011; Odom 2000).

However, without effective planning and systematic intervention, children with social communication deficits (e.g., autism spectrum disorder [ASD]) may be at increased risk for social isolation and may miss opportunities to develop meaningful relationships with peers. Past research suggests that some children with ASD do not benefit from inclusive educational settings without additional planning and systematic instruction (Bellini and Akullian 2007; Cho Blair et al. 2007; Koegel et al. 2012; Williams White et al. 2007). Children with ASD may benefit from the increased opportunities to observe, initiate social interactions, and respond to the social and play bids of typically developing peers that inclusive preschool environments offer. However, additional supports and instruction for classmates with and without ASD may be essential.

Impairments in social communication and restricted and repetitive behaviors, and interests characterize ASD (American Psychiatric Association, Diagnostic and Statistical Manual of Mental Disorders 2013). Without effective intervention, these delays can obstruct a child's meaningful participation in educational settings (Bono et al. 2004; Charman et al. 2005). Children with ASD often lack both functional (e.g., pointing at a 
desired toy to request access) and pragmatic (e.g., initiating play with others) social communication skills that can contribute to restricted age-appropriate play skills and limit language environments (Carter et al. 2005). Social pragmatic communication deficits can contribute to social isolation and reduced opportunities to engage socially (Stella et al. 1999; Wetherby et al. 2007). In addition, delayed symbolic play, functional toy use, and spontaneous independent play can prevent the development of parallel and cooperative play (Macduff et al. 1993; Pierce-Jordan and Lifter 2005). Moreover, as observed in other children with functional communication delays, delayed communication typically co-occurs with increased challenging behavior (Powell et al. 2006) which can decrease opportunities for positive peer interactions. Effective interventions that address the social communication deficits of ASD may allow the teachers and other early childhood professionals to maximize the potential benefits of inclusive preschool.

A number of literature reviews have been conducted to summarize the goals, procedures, and outcomes of studies evaluating interventions to improve the social communication skills for children with ASD from infancy to school age. In 2009, Spreckley and Boyd completed a meta-analysis specifically aimed at evaluating applied behavioral analysis (ABA) interventions for children with ASD, ages 18 months to 2 years; however, the review encompassed a greater breadth of adaptive behavior skills. Similar meta-analyses exist that summarized intervention studies across multiple domains such as challenging behavior, communication, or social skills (Kuppens and Onghena 2012; Reichow 2011; Virues-Ortega 2009). In 2007, Bellini et al. provided a meta-analysis of social skill interventions for children with ASD, and similar meta-analyses have surfaced with a broad age-range from early childhood to adolescence (e.g., Bellini and Akullian 2007; Wang and Spillane 2009). Additionally, literature reviews have summarized focused interventions addressing social communication skills, such as video modeling or the picture exchange communication system (PECS) (e.g., Bellini and Akullian 2007; Flippin et al. 2010). Further, in the 1990s, literature reviews emerged to examine practices in inclusion classrooms (e.g., Mesibov and Shea 1996). Recently, Goldstein et al. (2014) completed a review to determine the best practices for examining efficacy of interventions for social skills in preschoolers with ASD. To our knowledge, none of the aforementioned reviews focused specifically on social communication interventions for preschool children with ASD in inclusive preschool settings. The current study will use current recommendations for determining rigor and experimental validity, but is unique in its ability to report the efficacy of social communication interventions for children with ASD specifically in inclusive settings.

The purpose of the current review was to examine the effectiveness of social communication interventions geared specifically at increasing the child with ASD's ability to interact successfully with typically developing peers in preschool classrooms. To easily compare between studies, this review includes only those studies using single-subject design methodology. Single-subject methodology has been established as a powerful way to examine the utility of social communication interventions for young children with ASD (Goldstein et al. 2014). In addition, the current review summarizes literature published between 2005 and 2012. In 2004, the Individuals with Disabilities Act (IDEA) was reauthorized to reiterate the importance of free and appropriate public education (FAPE) for children with disabilities, and a key tenant of this legislation was to emphasize the importance of children with disabilities to be educated in their least restrictive environments (IDEA, 2004). Researchers responded to the changing classroom environment during the subsequent years and research with a focus on inclusive environments emerged (Odom et al. 2012). This review aimed to capture both changes in research focus after 2004 and changes in classroom makeup as rates of children diagnosed with ASD increased for children born in the 2000s (Boyle et al. 2011).

This paper aimed to address the following a priori research questions:

1. What is the existing research on social skills supports for young children with ASD in inclusive settings?

2. What are the results of existing intervention research on social skills for children with ASD in inclusive settings?

3. What are potential directions for future research?

The remainder of this paper is comprised of three sections. First, the methodology used for our systematic search of the literature is presented. Next, the review provides results of the data extraction including participant demographics, intervention setting, intervention type, results, and efficacy. Table 1 provides a summary of the results of the data extraction. Next, we offer interpretation of the results of our meta-analysis and a discussion of future research in the discussion section. Finally, we provide a brief conclusion of findings.

\section{Methods}

Figure 1 provides the reader with an overview of the main steps of our systematic search and study selection procedures, and reports the exact number of articles included and excluded at each phase of the search and data entry.

\section{Search Procedures}

Systematic searches were completed using four electronic databases: Education Resources Information Center (ERIC), Academic Search Premier, PsychINFO, and Medline. In all databases, the following search term combinations were 


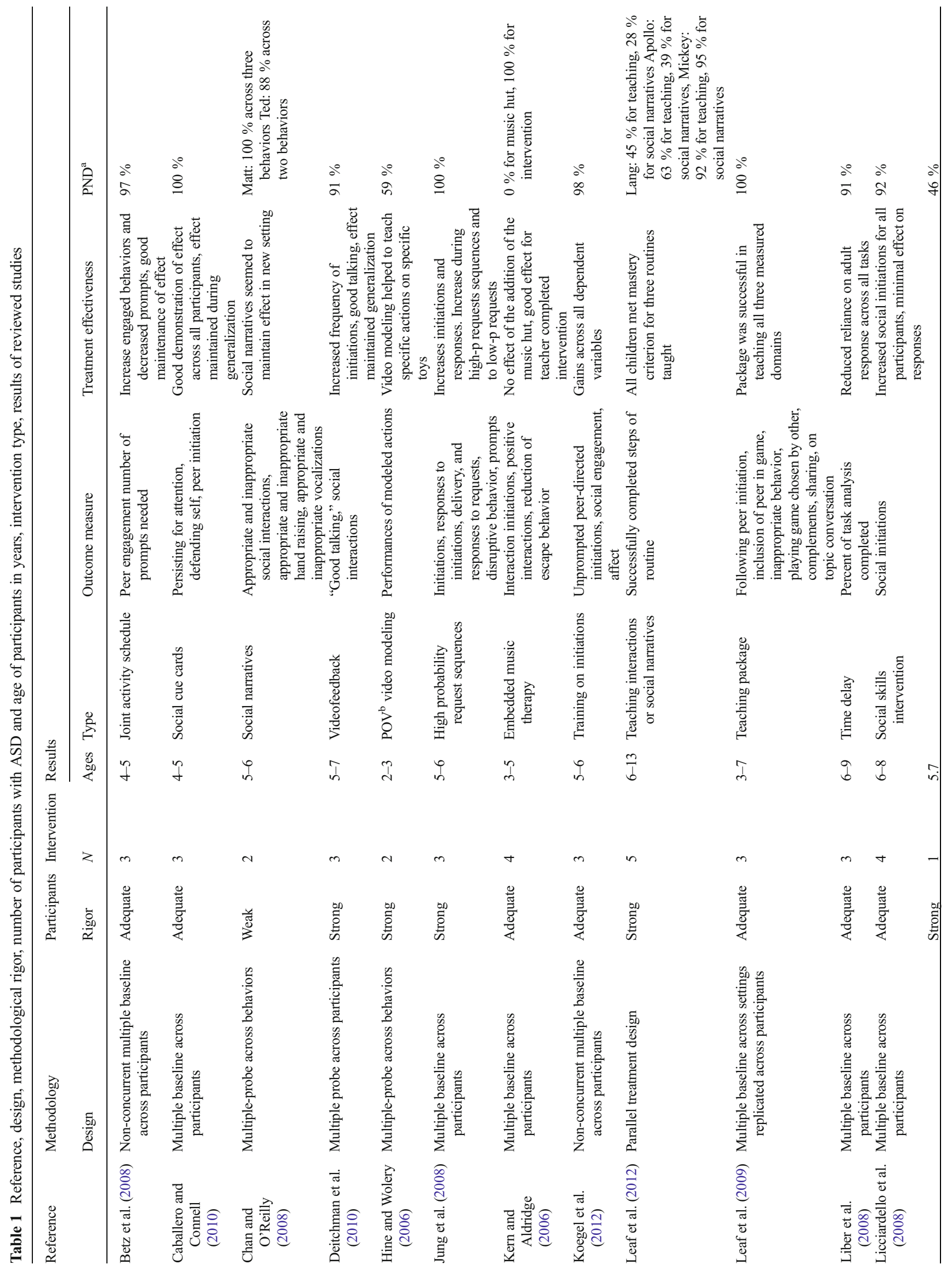




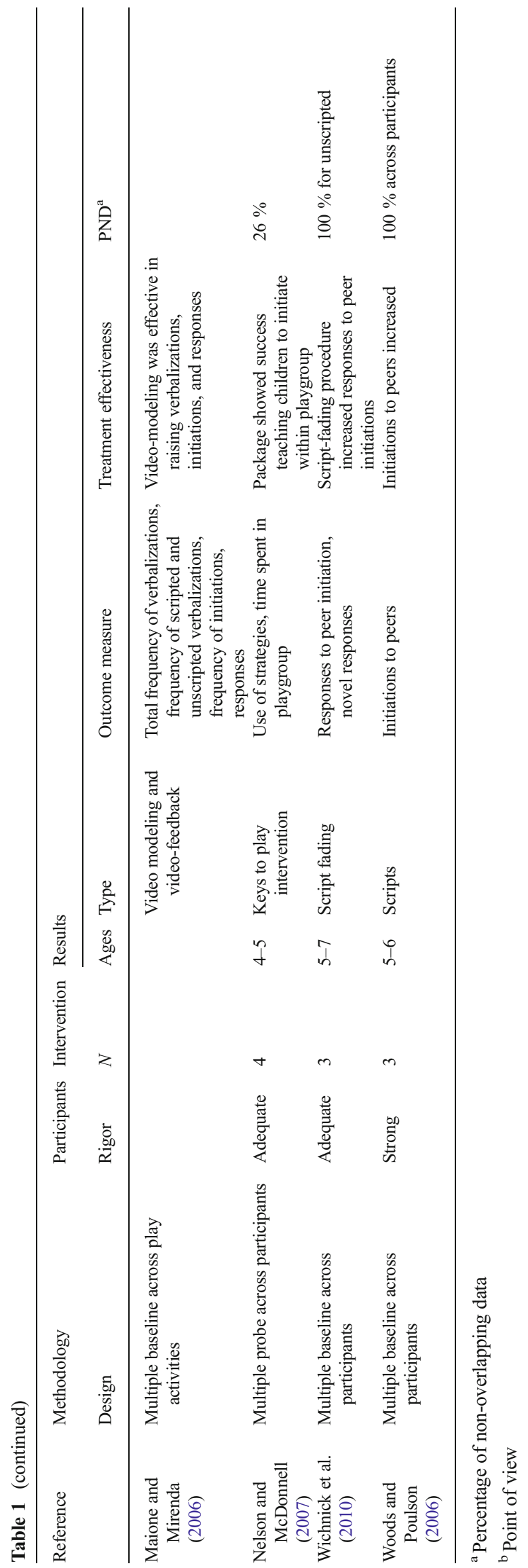

entered: ("Autism" or "ASD" or "Pervasive developmental disorder-not otherwise specified; PDD-NOS" or "Aspergers") and ("preschool" or "naturalistic setting") and ("play" or "communication" or "social skills" or "inclusion" or "strategy" or "classroom" or "peer interaction") in the keywords field. The abstracts of the returned studies were read to ascertain research method, and those studies using single-subject research were retained. Duplicate studies were removed, and those studies using single-subject design were then coded using the coding protocol. The first author completed electronic hand-searches of all authors and journals with more than one return across the years included in this review (20052012) to identify additional articles for possible inclusion. All searches by the first author took place between January 2013 and April 2013, and all reliability searches completed by coauthors took place between April of 2013 and September of 2013. Reliability coding and discussion amongst coauthors took place between September of 2013 and January of 2014. A total of 141 abstracts were selected for potential inclusion before examination with the inclusion criterion.

\section{Inclusion Criterion}

In order to be included in this review, the study needed to meet a set of inclusion criteria. Requirements for inclusion were (a) publication in an English language peer reviewed journal between the years 2005 and 2012, (b) utilized a singlesubject research design, and (c) included at least one participant diagnosed with an ASD between the ages of 3-6 years. Because these studies were all completed before the publication of the Diagnostic and Statistical Manual of Mental Disorders, Fifth Edition (DSM-5), inclusion of an ASD diagnosis/ educational classification was based on the diagnostic criterion outlined in the Diagnostic and Statistical Manual of Mental Disorders, Fourth Edition (DSM-IV), which included children with a diagnosis of Asperger syndrome and pervasive developmental disorder not otherwise specified (PDD-NOS) (American Psychiatric Association 2000; American Psychiatric Association 2013). The age range of 3-6 years for the target child (ren) was selected to capture preschool-aged children with an ASD who would be more likely to demonstrate verbal skills. Interventions had to be implemented to improve (a) social skills, (b) peer communication, or (c) play. All studies needed to assess the effects of the intervention in an inclusive setting in the USA. Inclusive settings were defined as having access to peers in the target child's least restrictive environment. Generally, interventions were applied with typically developing peers; however, two studies (Liber et al. 2008; Wichnick, et al. 2010) were included that measured target child interactions with trained peers who were not typically developing. Studies that implemented intervention in a clinical setting and assessed generalization to settings with typically developing peers were included. 
Fig. 1 Search and reliability procedures

\section{Identification}

Screening

Full-text Review
Studies were excluded from this review if the intervention did not address skills required for peer interaction and if the study failed to report application of social skills with typically developing peers. Studies where the dependent variable focused solely on mastery of intervention components were not included. For example, Cihak et al. (2012) was eliminated because it reported child correct completion of the steps of the PECS but did not report data for the effect of the PECS on social interaction with peers. Studies that evaluated the impact of their intervention on non-social classroom skills, for example, manding (i.e., requesting) for objects (e.g., Betz et al. 2011;

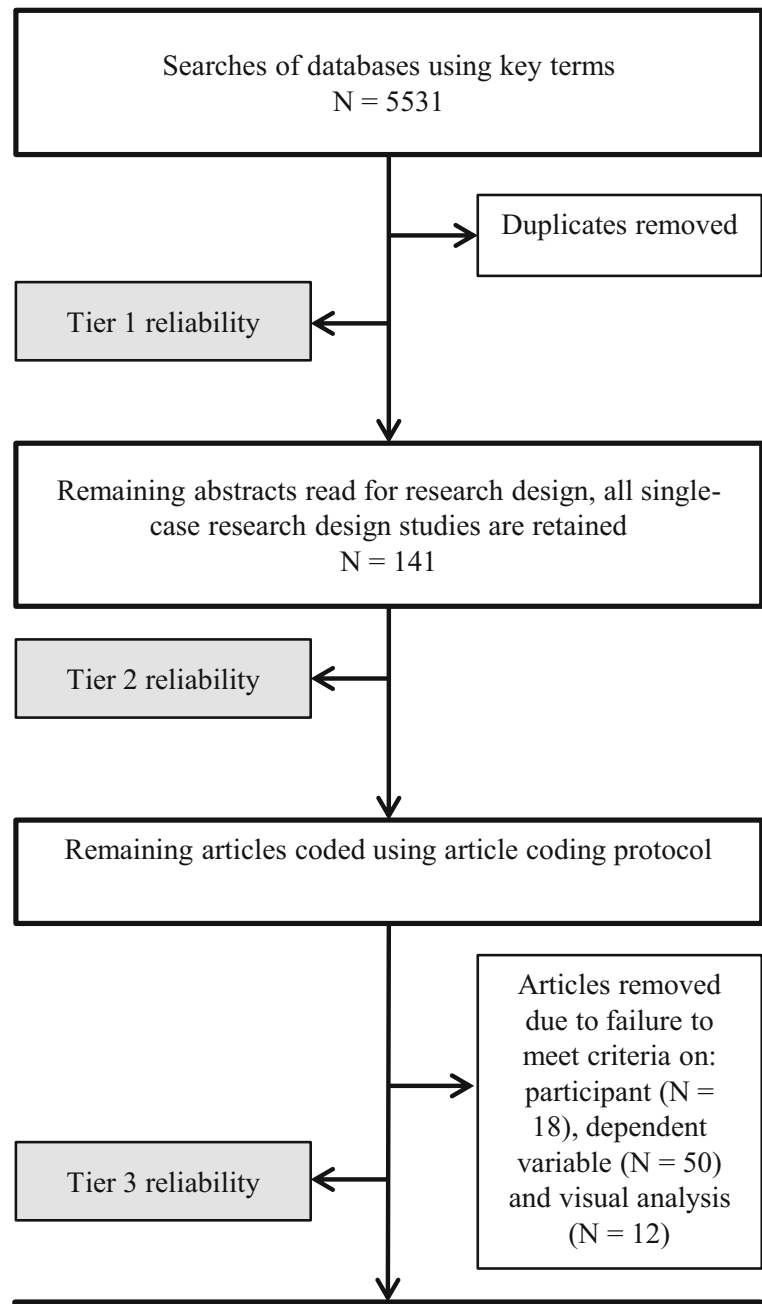

Reliability data collected and analyzed. Studies with disagreement $(\mathrm{N}=12)$ were discussed.

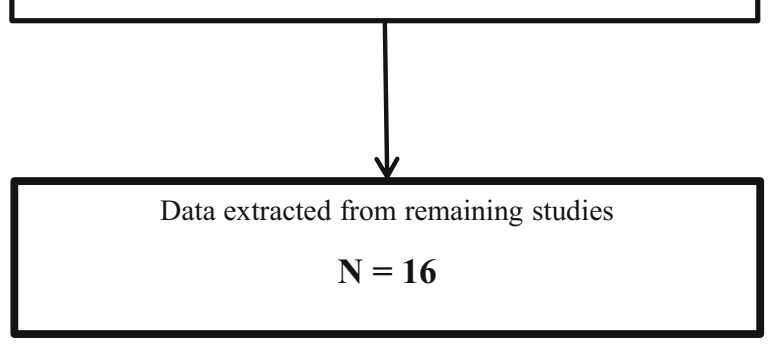

Thomas et al. 2010), were not included as the skills targeted did not apply directly to peer engagement or interaction. Finally, visual analysis was completed on all studies, and studies needed at least a moderate effect to be included in the review according to the guidelines established in Horner and colleagues (2005). Sixteen articles met the criteria for inclusion.

\section{Reliability Protocol}

Coauthors completed reliability protocols in three tiers to mirror the search procedure completed by the first author. 
In the first reliability tier, the second, third, and fourth coauthors independently completed the searches of the electronic databases. These coauthors replicated the original searches split by database (i.e., the second author searched PsychINFO, the third author searched ERIC, and so on). These coauthors forwarded the results of their searches to the first author for coding of any newly identified studies. In the second reliability tier, the third author independently recoded $70 \%$ of the search results and the fourth author independently recoded $30 \%$. The third and fourth authors decided on article inclusion based on the first four sections of the inclusion-coding sheet but did not perform visual analysis on the resulting studies. In the third reliability tier, once all articles had been coded for inclusion by the first author and at least one coauthor, the second author reviewed the articles marked as included and completed visual analysis of graphs included in the articles. The first and second authors then discussed articles that lacked agreement until consensus on inclusion or exclusion was reached. A total of 35 studies were discussed, those not selected by the first author but selected by a coauthor, those selected by a coauthor but not originally selected by the first author, and those selected by both. Three of the studies with disagreement were retained for the study and 15 were permanently removed. A list of excluded articles is available from the first author by request.

\section{Data Extraction}

Data were extracted by the first author and were reported on the following variables: (a) methodology (design and rigor), (b) participants (number, age, and gender), (c) intervention (type and interventionist), and (d) results (outcome measure, success estimate, and percent non-overlapping data (PND). Results are presented in Table 1, and the in-text summary in the results section will provide readers with a brief overview, across intervention types, of the results, as well as more detailed information about two exemplars of that particular intervention category.

\section{Dependent Variables}

Dependent variables were categorized by the following categories: social communication, social pragmatics, or play skills. Studies were defined as measuring social communication if they looked at increasing communication attempts to peers (i.e., verbalizations, on topic conversation, and invitations to play). Social pragmatics included studies that looked at nonverbal social skills such as eye contact, sharing, or turn taking. Play skills looked at skills directly related to play like actions on play objects.

\section{Independent Variables}

Independent variables ranged from antecedent strategies such as time-delay or high probability request sequences, visual schedules, social narratives, video modeling, or video selfmodeling. Additional studies used peer modeling or teaching packages made up of several intervention components.

\section{Rigor of Intervention}

Rigor of design was decided based on an adaptation of Reichow et al. (2008) guidelines for assessment of the rigor of interventions on ASDs. Reichow et al. (2008) used six primary indicators and five secondary indicators to determine if the rigor of the intervention was strong, adequate, or weak. The primary indicators included sufficient information given about participant characteristics (i.e., age and gender diagnosis), manualized or replicable description of the independent variable, operational description of the dependent variable under study, adequate results of visual analysis, and demonstration of experimental control. Reichow and colleagues (2008) identified the secondary indicators as documentation of inter-observer agreement, Kappa, procedural, or treatment fidelity; the use of blind raters to collect data; a generalization or maintenance phase; and the use of social validity.

Under Reichow and colleagues' specifications, an intervention is determined to be strong if it received high ratings on all primary indicators and at least four secondary indicators. A study is judged to be adequate if it has high ratings on four or more primary indicators and at least two secondary indicators, and weak if it received fewer than four high ratings. Studies were not removed from further analysis based on the rigor determination; however, rigor is reported in the results table.

\section{Visual Analysis}

The first and second authors applied standards for visual analysis of single-subject data (Gast and Ledford 2010; Horner et al. 2005). Articles were determined to be weak if there were insufficient data collected per phase (at least three data points were required for a moderate strength of design) or insufficient demonstrations of effect (less than three). Moderate designs showed at least three data points per phase and at least three demonstrations of effect at three different points in time. Strong designs had five data points or more per phase and at least three demonstrations of effect. Weak designs were removed from further analysis.

\section{Percent non-Overlapping Data}

The first author computed effect sizes for the resulting studies using PND using the methods described by Parker et al. 
(2011). PND was calculated from the line graphs by using a pencil to draw a line from the highest baseline data point appearing in the "A" phase horizontally across the graph through the " $\mathrm{B}$ " intervention phase and dividing the total number of intervention data points that appeared above the resultant line by the total number of intervention data points. The percentages that were obtained were then averaged across the experimental phases of a design. In the event that the design featured a " $C$ " phase, the design was examined to determine the function of the " $\mathrm{B}$ " phase. If the " $\mathrm{B}$ " phase functioned as training phase or used a prompt or support that was not in place for all participants, then PND was calculated from the baseline to the " $\mathrm{C}$ " phase. If the $\mathrm{B}$ phase was a standard intervention data, then PND was calculated to mirror visual analysis, first from phase " $\mathrm{A}$ " to phase " $\mathrm{B}$ " and then from phase "B" to phase "C". PND was not calculated for generalization or maintenance (i.e., follow up) assessment data. No studies included in this review used a single-subject reversal design.

\section{Reliability Procedures}

The second author completed reliability coding on $30 \%$ of randomly selected studies. The second author made estimations of study rigor using the Reichow et al. guidelines (2008). The second author also checked all cells of Table 1 for the accurate reporting of included studies. Reliability was calculated by summing the total data points of non-overlapping data established by the first author and dividing the sum by the sum established by the second author, then multiplying the result by 100 . The total reliability was $99 \%$ between the two authors. No disagreements were found on other cell data on the matrix or in table two.

\section{Results}

Participants and Intervention Settings

Table 1 reports the results of the data extraction. Table 1 reports results for design, rigor, number and age of participants, intervention type, results, and PND.

Across the 16 included articles, there were 44 preschool age (i.e., 3-6 years of age) participants with ASD diagnoses. Diagnoses of ASD included autism $67 \%$, autistic disorder $18 \%$, PDD-NOS $11 \%$, and Asperger syndrome $4 \%$. Only five of the 16 included studies directly reported standardized scores for language or cognitive level of participants (e.g., reported scores on the Clinical Evaluation of Language Fundamentals-Preschool (CELF-P) or the Peabody Vocabulary Test) (Dunn et al. 2007; Wiig et al. 2004). Eight of the 16 studies reported verbal level observationally (i.e., "had basic verbal skills") and three of the 16 studies did not give any information about the verbal or cognitive level of the participants. Primary settings for these studies included classrooms (12 studies), "play dates" at home (three studies), and one study conducted primarily in an intervention room (Leaf et al 2012). Classrooms ranged from general education or childcare to intensive behavioral settings. For all participants, $7 \%$ of their classrooms were special education classrooms, $7 \%$ were autism-specific classrooms, $25 \%$ were inclusive classrooms, $41 \%$ were general education public classrooms, $5 \%$ were Head Start classrooms, $7 \%$ were community child care centers, $2 \%$ were summer camps, and $4 \%$ were university-based lab schools.

Implementation of interventions took place across a variety of settings and contexts. Of the 12 studies completed in the classroom, four studies were completed during center time (e.g., where children rotate between a few pre-selected activities for a discrete amount of time), four studies were completed during recess or outside-play, two studies were completed during free play, one took place during circle time, and one at lunch. Generalization or maintenance assessment also varied in setting across studies. Eleven of the 16 studies included a generalization or maintenance phase. Of these, two assessed generalization to peers, five assessed maintenance in the same setting, three assessed generalization to a novel setting or materials, and one study assessed maintenance after some time had elapsed.

Teachers ( $24 \%$ of studies), researchers (50\% of studies), peers (13\% of studies), and educational assistants (13\% of studies) implemented interventions. The ways that typically developing peers were involved differed. Twelve percent of studies had a peer present during intervention but not trained. Fifty percent of studies measured interactions with peers in a naturalistic setting (i.e., free play), $19 \%$ of studies trained peers as models or interventionists, and $19 \%$ of the studies used a play date model (e.g., the participants generalized or practiced skills in a play date with a familiar peer in their home).

\section{Dependent Variables}

Due to the search procedures of this literature review, a majority of the included studies had similar or comparable dependent variables. All dependent variables focused on skills needed to interact with peers in a preschool classroom. Most dependent variables could be categorized as social communication (27\%), social pragmatics (30\%), or play skills ( $27 \%$ ). A small percentage of the dependent variables also assessed challenging behavior as a secondary outcome $(16 \%)$. Discrete dependent variables were diverse across studies, with the largest percentage of studies focused on initiations to peers (42\%). Multiple studies also assessed engaged play with peers $(21 \%)$, positive social interactions $(21 \%)$, and 
conversations with peers $(16 \%)$. Table 2 indicates the skills supported by each study's interventions.

\section{Interventions}

A majority of the interventions included in this review used modified principles from ABA, which is a systematic approach that applies the scientific principles of behavior to identify and manipulate environmental variables to change socially valid behavior (Baer et al. 1968). Such interventions utilize mechanisms such as reinforcement to strengthen desired behaviors and discrete stimuli to increase the frequency of such behaviors (e.g., initiations to a peer or vocalizations) as well as other strategies to decrease unwanted behaviors such as problem behavior or stereotypy (e.g., Koegel et al. 2009; Thomas et al. 2010). Two of the included studies used prompting, and one study used the concept of behavioral momentum. Three studies used video modeling or video self-modeling, two studies used peer modeling, and two studies used a teaching package made up of several intervention components. For example, Leaf and colleagues (2009) used a teaching package made up of modeling, priming, and a token economy.

\section{Research Design}

Due to inclusion criteria, all studies included in this review used a single-subject research design. A majority of the included studies used multiple baseline designs (76\%) allowing for easier comparison across results. Most of the multiple baseline designs were across participants, but multiple baseline designs across behaviors, settings, and activities were also represented. Four of the included studies used a multiple probe design, either across participants or behaviors. One study used a parallel treatment design (Leaf et al 2012).

\section{Study Results}

Outcomes of the included interventions were diverse. PND scores ranged from 11 to $100 \%$. In addition, results were variable across participants. While 13 of the 16 included studies featured a maintenance or generalization assessment phase, data were not analyzed for effect size in these phases.

\section{Antecedent Strategies}

Eleven of the 16 included studies used an antecedent strategy. For the purpose of this review, antecedent strategies refer to all ways to prompt responding through manipulation of the routine or environment before the targeted behavior is occasioned (Harrower and Dunlap 2001).

\section{Visuals}

Four studies used visuals in their interventions. Visuals, whether small cards with black and white or color line drawings or photographs, picture or photo activity schedules or social narratives, use simple pictorial representations or

Table 2 Dependent variables for included studies

\begin{tabular}{|c|c|c|c|c|c|c|c|c|c|}
\hline & $\begin{array}{l}\text { Peer } \\
\text { engagement }\end{array}$ & $\begin{array}{l}\text { Peer } \\
\text { initiation }\end{array}$ & $\begin{array}{l}\text { Social } \\
\text { pragmatics }\end{array}$ & $\begin{array}{l}\text { Social } \\
\text { Interactions }\end{array}$ & $\begin{array}{l}\text { Play } \\
\text { Skills }\end{array}$ & $\begin{array}{l}\text { Challenging } \\
\text { behavior }\end{array}$ & Affect & $\begin{array}{l}\text { Social } \\
\text { Routines }\end{array}$ & Verbalizations \\
\hline Betz et al. (2008) & $\mathrm{X}$ & & & & & & & $\mathrm{X}$ & \\
\hline Caballero and Connell (2010) & & $\mathrm{X}$ & $\mathrm{X}$ & $\mathrm{X}$ & & & & & \\
\hline Chan and O’Reilly (2008) & & & $\mathrm{X}$ & & & & & & $\mathrm{X}$ \\
\hline Deitchman et al. (2010) & & $\mathrm{X}$ & & & & & & & $\mathrm{X}$ \\
\hline Hine and Wolery (2006) & & & & & $\mathrm{X}$ & & & & \\
\hline Jung et al. (2008) & & $\mathrm{X}$ & & $\mathrm{X}$ & & $\mathrm{X}$ & & & \\
\hline Kern, P., Aldridge, D. & $\mathrm{X}$ & $\mathrm{X}$ & & $\mathrm{X}$ & & $\mathrm{X}$ & & & \\
\hline Koegel et al. (2012) & $\mathrm{X}$ & $\mathrm{X}$ & & & & & $\mathrm{X}$ & & \\
\hline Leaf et al. (2012) & & & $\mathrm{X}$ & & & & & $\mathrm{X}$ & \\
\hline Leaf et al. (2009) & & $\mathrm{X}$ & $\mathrm{X}$ & & $\mathrm{X}$ & $\mathrm{X}$ & & & $\mathrm{X}$ \\
\hline Liber et al. (2008) & $\mathrm{X}$ & $X$ & & & $\mathrm{X}$ & & & & $\mathrm{X}$ \\
\hline Licciardello et al. (2008) & & $X$ & & & & & & & \\
\hline Maione and Mirenda (2006) & & $X$ & & & & & & & $\mathrm{X}$ \\
\hline Nelson and McDonnell (2007) & $\mathrm{X}$ & & & & & & & & $\mathrm{X}$ \\
\hline Wichnick et al. (2010) & $\mathrm{X}$ & & & & $\mathrm{X}$ & & & & \\
\hline Woods and Poulson (2006) & & $\mathrm{X}$ & & & & & & & \\
\hline
\end{tabular}


images and phrases to break down complicated skills such as greeting a peer into discrete and manageable behaviors (Bondy and Frost 2001; Gray and Garand 1993). In a nonconcurrent multiple-baseline across participants, Betz et al. (2008) used joint activity schedules to increase engaged play with peers. The joint activity schedule adapted the typical visual schedule to apply to a child with ASD and his/her peer, so that the peer and the target child worked together to move through the schedule. The study had strong effect across participants in raising the level of engagement with peers in participants, with PND of $97 \%$.

Caballero and Connell (2010) used social cue cards to teach social concepts to participants. The study looked at a different skill for each participant, and the skills included: (a) persisting for attention, (b) defending self, or (c) initiation to peer in a multiple baseline design across participants. The study used visual cue cards to prompt appropriate responding for these skills. For example, for the participant a target skill of "defending self", the card might read, "give it back" with a corresponding cartoon picture. The intervention had a strong effect with $100 \%$ PND across participants.

\section{Video Modeling}

In this review, three studies used some form of video modeling in an inclusive preschool setting. These included studies intervening on social initiations (Deitchman et al. 2010), play skills (Hine Hine and Wolery 2006), and social language (Maione and Mirenda 2006). Deitchman et al. (2010) used video feedback to augment an existing self-management intervention. Video feedback was introduced through presenting participants with two video clips, one that showed them successfully completing a social interaction and one that had errors and asking the participant to discriminate between the two video examples. Frequency of successful interactions was measured in a multiple baseline across participants. The addition of the video feedback sessions increased initiations. PND for graphed data was $91 \%$.

Hine and Wolery (2006) used point of view (POV) modeling to teach play skills to children with ASD in a preschool classroom. Specific actions on play objects commonly found in the sensory table were taught through videos filmed from the POV of the participant. Generalization data were taken during center time with typically developing peers. Data were collected for a multiple baseline design across participants and activities. Moderate effect was shown with high variability of data. PND for graphed data was $59 \%$ with exclusion of data points taken during practice sessions.

\section{Scripts}

In this review, we identified two studies that used scripts to intervene on social or play skills. Wichnick et al. (2010) used a script fading procedure to increase correct responses to initiations from typically developing peers in a preschool classroom. By fading the script used to appropriately respond to the peer, the study increased novel or independent responses to the peer. In a multiple-baseline design across participants, Wichnick et al. (2010) had good success across participants, with PND for graphed data of $100 \%$ for both scripted and unscripted responses.

Woods and Poulson (2006) used scripts to increase initiations to typically developing peers by children with developmental disabilities. The study looked at the three participants with differing developmental disabilities; however, only the results of the child with ASD are reported for the purpose of this review. In a multiple baseline design across participants, the participant with autism showed $100 \%$ PND for increase in unscripted responses.

\section{Other Antecedent Strategies}

Jung et al. (2008) used the theoretical principles of behavioral momentum to allow children with ASD to respond to a highprobability (high-p) request sequence connected to social interaction. In this study, a series of preferred tasks or mastered activities such as, "put your hands on your shoulders," were followed by a low-probability (low-p) request such as, "invite a peer to play." In a multiple baseline across participant design, Jung and colleagues (2008) demonstrated moderate results across participants, with good maintenance of effect between the high-p and low-p requests. PND for this study was $100 \%$.

Liber et al. (2008) used time-delay to fade prompts when teaching children with ASD to demonstrate appropriate play skills with peers. Detailed task analyses were created for several social skills. Prompts for the next step of the task analysis were faded using 2-s intervals until the child was able to complete the step correctly without a prompt. The effects of the time delay intervention on percent of correctly completed steps of the task analyses were examined using a multiple baseline design across participants. The study found a good effect across interventions, with a PND of $83 \%$.

\section{Peer-Mediated}

While several studies in this review used trained peers as a part of their intervention, two studies used explicitly peer-mediated interventions. Nelson and McDonnell (2007) used the "Keys to Play" intervention to increase social interaction. In a multiple probe design across participants, this intervention package used a visual key to prompt, delivered by the child with ASD, to increase the use of targeted social interaction procedures by typically developing peers. The study worked to increase initiations to typically developing peers and had a weak effect across participants. The addition of a verbal 
prompt from the interventionist increased responding. PND for graphed data was $26 \%$.

Kern and Aldridge (2006) used a music therapy intervention paired with peer modeling. The study used a "music hut," which was a space in the outdoor play area of an inclusive school's playground. The interventionist targeted songs to the particular goals of each participant. The design featured two phases, one that was teacher-mediated and one that was peermediated. The teacher-mediated intervention used the music hut and resulted in a small increase for all participants. The peer "buddies" were trained by the teachers to mediate the intervention and the prompting from teachers was simultaneously withdrawn. In a multiple-baseline design across participants, peer-mediated intervention had a good effect with PND of $100 \%$.

\section{Packaged Interventions}

Two studies described in this review were packaged interventions. Leaf and colleagues (2009) used a teaching package to increase use of prosocial behavior. The intervention featured modeling, priming, a token economy, and coaching from a target typically developing peer. The effects of the intervention were evaluated using a multiple baseline design across skills. The package had an effect on the level of following peer initiation, including a peer in a game, playing a game chosen by another, complements, sharing, and on-task behavior across participants. PND for graphed data was $100 \%$.

Koegel et al. (2012) used an "initiations training" that was made up of a phase of adapted pivotal response training (PRT) followed by prompted initiations and scripts. This study attempted to improve generalization of gains in initiations. This design was evaluated in a multiple baseline design across participants, with an $\mathrm{ABAB}$ component to measure the effect of the initiations training specifically. The design showed $98 \%$ PND across participants; however, the third participant did not complete a phase of the design, which weakened its effect.

\section{Social Validity}

A majority (69\%) of the included studies did not report social validity measures. Of the studies that did report social validity, many different measures were used. Most studies used some kind of survey measure for teachers. For example, Deitchman and colleagues (2010) used a three point, pre-post rating scale administered to teachers to judge satisfaction with their intervention. Woods and Poulson (2006) used a short questionnaire, an "acceptance scale" to assess changes in peer acceptance of target children. An example of a non-surveybased social validity measure was the use of graduate student ratings of pre-post videos of play activities by target children (Hine and Wolery 2006).

\section{Discussion and Future Research}

The current systematic review of the literature examined studies on improving social communication skills for children with ASD in inclusive preschool classrooms. To target studies that were aimed at increasing the skills of children in inclusive classrooms, each of the 16 included studies featured a typically developing or more experienced peer, either as an intervention agent or during a generalization or maintenance assessment phase of the study. This review identified a range of effective interventions to improve the social communication skills for children with ASD in inclusive preschool classrooms. We discuss our findings and provide suggestions for future research on the following: (a) efficacy of interventions, (b) implications for practice and policy, and (c) limitations and future research.

\section{Efficacy of Interventions}

There is a current push in the field for formation, research, and implementation of evidence-based practices (Horner et al. 2005; Odom et al. 2003; Reichow et al 2008). The first research question of this literature review was to establish what portion of the sizable body of research on social communication interventions for children with ASD was directly applicable to young children served in inclusive settings. Results showed a range of acceptable interventions, representative of the larger body of literature on social communication and ASD. The second research question of this review looked to determine the effectiveness (i.e., effect size) of the identified interventions and draw conclusions from these results. Effect size was reported for all studies, but given the small number of studies meeting stringent inclusion criteria, further conclusions need to be drawn about the relevancy, stability, and generalizability of the included interventions.

The current review examined a range of interventions in differing social communication targets. Dependent variables in the reviewed studies generally addressed peer engagement (e.g., play with peers), peer initiation (e.g., invitations to play), and early social pragmatics (e.g., greetings and sharing). While the understanding that children with ASD face difficulty interacting socially seems valid, further research is needed to examine different topographies of social behavior in young children with ASD. While basic social skills like sharing, turn taking, and inviting to play are critical for success in preschool, participants may benefit from training on more advanced, higher order pragmatics such as telling jokes to obtain peer attention. In typically developing preschool populations, social competency extends beyond the ability to perform discrete prosocial behaviors and extends towards less discernible skills like forming friendships, reading subtle social cues, and observing social norms (Bauminger-Zviely et al. 2013; Stanton-Chapman et al. 2012). 
In addition, social behavior is also just one component of success in an inclusive preschool classroom. Other barriers for children may include challenging behavior, functional communication needs, and information processing (Crosland and Dunlap 2012; Ravet 2011; Von der Embse et al. 2011). Interventions that combine social skills training with secondary variables of challenging behavior or functional behavior are promising. For example, Jung and colleagues (2008) addressed a secondary variable of the reduction of challenging behavior. The intervention on initiations to peers used in this study included redirections of challenging behavior and reported levels of challenging behavior as a secondary variable. Nelson and McDonnell (2007) used a peer-mediated intervention to increase social interactions, but also tracked functional language use by target participants. Results from these studies indicate that secondary variables (e.g., challenging behavior) may in some cases be important for child progress on social dependent variables such as social initiations. Future research should focus on pairing secondary variables that may interfere with positive interaction with peers with social communication interventions in order to increase responding.

Results of this review showed mixed ability of interventions to be applied effectively in an inclusive setting. Additionally, the consistency of results varied across interventions and between different studies using the same intervention. Of the articles included in this analysis, visuals (i.e., visual schedules, social stories, and social cue cards) and scripts had the most consistently positive result on dependent variables, with PND ranging from 97 to $100 \%$. The interventions with the most variability across studies, which points to inconsistency of effect, are peer-mediated interventions (26-100 \% PND) and video modeling (46-91\% PND). Because of the stringent nature of the inclusion criterion for this review, there is no clear representation of studies with poor effect size, but the variability of success with popular interventions illustrates the necessity of both fidelity of implementation and consideration of participant populations. Further research is needed to determine critical components of interventions that allow them to fit well in inclusive preschool settings.

Two of the included intervention types had highly variable results. As is represented in the larger body of ASD research, a significant portion of these studies included use of video modeling. Past research supports the use of video modeling to address the core symptoms of ASD, including challenging behavior and social communication delays (Bellini and Akullian 2007). These positive effects have been shown to generalize across settings and maintain over time (Bellini and Akullian 2007). Video modeling has also had a good effect for the modeling of complex social interactions such as sharing a toy (e.g., Marzullo-Kerth et al. 2011). Video modeling is a topical area of research however in this review has shown mixed results. The finding that video modeling has varied results for interventions could point to barriers to use of this intervention in inclusive settings. Further analysis of participant characteristics should be undertaken to determine when and for whom video modeling interventions are effective.

Additionally, a large number of reviewed studies made direct use of peers, such as in peer coaching or peer modeling. Involving the peer in implementation of the intervention is thought to be effective in reducing two barriers to peer inclusion, social interactions with peers and peer acceptance (Betz et al. 2008; Ganz and Flores 2008; Kohler et al. 2007). Peer acceptance is largely missing from this body of research as a primary variable. Some information about the effect of the interventions on peer acceptance comes from social validity ratings. For example, Woods and Poulson (2006) measured typically developing peer attitudes about peers with ASD with a pre-post questionnaire. Involving a typical peer variable in the research question would allow researchers to embed questions of ecological social validity within interventions.

As has been noted in several topical literature reviews, it is difficult to generalize across studies because of the heterogeneity of behaviors and delays in children with ASD (Schreibman 2000; Goldstein et al. 2014). ASDs are a broad range of developmental disabilities that can differ widely in characteristics, behavioral topographies, and outcomes (Fombonne 2003; Newschaffer et al. 2007). Methodologies are needed to decipher goodness of fit of evidence-based interventions to distinct sub-populations in ASD. This barrier is well noted in this review, as several of the included studies show largely different effect size between participants receiving the same or similar treatment (e.g., Leaf et al. 2012; Nelson and McDonnell 2007). Those studies most successful across participants had both a fairly small subset of individuals with ASD in their study and a high level of systemization of intervention. Future research should focus on determining characteristics of participants and environments that dictate the likelihood of the success of current interventions for specific participant subsets.

Additional issues pertaining to the heterogeneity of children with ASD come from the classroom setting. Across studies there was a wide range of classroom makeup, teacher training, classroom size, philosophy, and dosage of interventions. Further research is needed to investigate preschool classroom characteristics that may contribute to success for children with ASD. There are key needs of classrooms to be able to provide effective settings for interventions on social skills. Teacher training in particular is a barrier for the successful inclusion of children with ASD (Morrier et al. 2010). Individuals who were highly trained in working with children with ASDs, which may not be representative of early childhood educators, implemented over half of the studies included in the present review. Additionally, a majority of the studies completed training or intervention in a clinical or isolated setting and either introduced intervention into a peer setting 
or assessed participant skill generalization to a peer setting. A few of the included studies assessed generalization to peers, but had only one familiar peer available for generalization of skills. In the typical classroom, there are other factors controlled for in these studies such as classroom noise, teacher/ child ratio, and unpredictability of peers that may influence responding. Future research that is embedded in the natural classroom environment and that promotes sustainability of teacher use of interventions in the natural classroom environment is critical.

\section{Implications for Practice and Policy}

Research has established that social communication is critical for success in the preschool classroom and has direct correlates with later academic achievement (McClelland and Morrison 2003; Odom et al. 2006). Additionally, for children with special needs, participation in preschool classrooms alongside typically developing peers has been shown to increase opportunities to develop important social and preacademic skills (Guralnick et al. 1996; Ferraioli and Harris 2011). Current research has also established that for children with autism to successfully participate in inclusive settings, additional supports are often needed. For educators in inclusive settings, results of this review indicate suggestions for applicable interventions. Early childhood teachers working with preschoolers with ASD should access interventions that have shown a good effect in inclusive settings. Results of this review indicate several interventions that can be integrated into classroom routines and that show a good effect on a variety of desired behaviors.

Evidence that the need for effective social communication interventions for this population had increased due to changes in legislation and typical child placement decisions provided much of the impetus for this review. Findings indicate that interventions exist that, when implemented with fidelity, have a positive effect on meaningful engagement in preschool classrooms for children with ASD. Results of this review have implications for policy. Primarily, the range of efficacy of interventions included in this review indicates the need for inclusive settings to include access to evidence-based practices on social communication for children with ASD. Furthermore, teacher training and parent involvement should continue to include strategies for reducing barriers to meaningful interactions with peers in the preschool classroom including communication, challenging behavior, and peer acceptance.

\section{Limitations and Future Research}

The studies in this review with the strongest results were often those with the most experimental rigor. Many of these studies used a teaching-package or self-written intervention that was formed out of evidence-based components (e.g., Leaf et al. 2009, 2012; Nelson and McDonnell 2007). Strong studies often used components of ABA such as reinforcement schedules or fading of scripts or stimuli (e.g., Jung et al. 2008). Studies that did not directly intervene using an ABA principle still often used ABA components indirectly. For example, Deitchman et al. (2010) used a systematic preference assessment to identify potential reinforcers and used reinforcement principles throughout the intervention. ABA has been shown to be effective for intervention on many components of ASD; however, it is consistently noted in the literature that the dosage required of early intensive ABA sometimes is not possible in a naturalistic environment like that of an inclusive preschool classroom (Jones et al. 2007; Rispoli et al. 2013; Tiger et al. 2006). Although the interventions reviewed here were focused, rather then comprehensive ABA intervention, future research should examine ways to support teacher use of such evidence-based strategies in inclusive preschools.

Differences in effect size between participants on the same intervention may also be related to participant characteristics. Dosage or intensity of intervention may need to be modulated based on participant functioning, for example, higher intensity interventions may be required for lower functioning participants (Hus and Lord 2013; Reichow 2012). Only $30 \%$ of the included studies reported measured cognitive or language levels, with $47 \%$ of the studies noting observational information about functioning. This missing information in the literature may point to a need for researchers to be more explicit about participant characteristics in order to allow for correct dosage and intensity of intervention, as well as to provide information to the consumers about the utility of the intervention to particular populations. Another characteristic of research participants not specified in this body of research is prior treatment. A majority of the included articles did not specify what sort of treatment the participant had been exposed to prior to participation in the study. For participants that may have been receiving intensive ABA therapy, transfer of these skills may have changed outcomes.

In a meta-analysis on social validity ratings for social skill interventions for preschool aged children, authors reported a $27 \%$ rate of studies reporting social validity from 1970-2008 (Hurley 2012). The current study represents a similar trend. Only $31 \%$ of the included studies measured social validity. The addition of social validity measures strengthens the conclusions that can be made about utility of the studies, predicts the likelihood that teachers adapt studies to everyday classroom practices, and provides feedback to researchers about perceived effects of intervention (Goldstein et al. 2014; Hurley 2012). When researching interventions that are novel in the classroom setting, but well established clinically, social validity is especially important because it speaks to the practitioner's perceptions of goodness of fit. Further research is needed on the role of social validity in intervention research 
and the extent to which social validity measures are completed in a valid manner. The presence of social validity measures listed by Reichow and colleagues (2008) as a secondary indicator for rigor of design, and Goldstein and colleagues (2014) noted the importance of social validity when they form their framework for the evaluation of interventions for this particular population.

\section{Conclusion}

The current review found a diverse body of interventions working to support social success for children with ASD in inclusive preschool classrooms. While no one type of intervention could be selected as the most effective and the range of effect size was considerable, research points to young children with ASD as having a wide range of support needs, making generalization of intervention outcomes difficult. Future research should focus on interventions that are easily embedded into classroom routines and have opportunities for direct peer involvement. The finding that studies with a good experimental rigor translated most often to strong results illuminates the need for transfer of fidelity of implementation into the classroom environment.

\section{References}

American Psychiatric Association. (2000). Diagnostic and statistical manual of mental disorders (4th ed., text rev.). Washington, DC: Author.

American Psychiatric Association. (2013). Diagnostic and statistical manual of mental disorders (5th ed.). Arlington: American Psychiatric Publishing.

Baer, D. M., Wolf, M. M., \& Risley, T. R. (1968). Some current dimensions of applied behavior analysis. Journal of Applied Behavior Analysis, 1, 91-97.

Bauminger-Zviely, N., Eden, S., Zancanaro, M., Weiss, P. L., \& Gal, E. (2013). Increasing social engagement in children with highfunctioning autism spectrum disorder using collaborative technologies in the school environment. Autism, 17, 317-339.

Bellini, S., \& Akullian, J. (2007). A meta-analysis of video modeling and video self-modeling interventions for children and adolescents with autism spectrum disorders. Exceptional Children, 73, 264-287.

Betz, A., Higbee, T. S., \& Reagon, K. A. (2008). Using joint activity schedules to promote peer engagement in preschoolers with autism. Journal of Applied Behavior Analysis, 41, 237-241.

Betz, A. M., Higbee, T. S., Kelley, K. N., Sellers, T. P., \& Pollard, J. S. (2011). Increasing response variability of mand frames with script training and extinction. Journal of Applied Behavior Analysis, 44, $357-362$.

Bondy, A., \& Frost, L. (2001). The picture exchange communication system. Behavior Modification, 25, 725-741.

Bono, M. A., Daley, L. T., \& Sigman, M. (2004). Relations among joint attention, amount of intervention and language gain in autism. Journal of Autism and Developmental Disorders, 34, 495-505.
Boyle, C., Boulet, S., Schieve, L., Cohen, R., Blumberg, S. J., YearginAllsopp, M., et al. (2011). Trends in the prevalence of developmental disabilities in US children, 1997-2008. Pediatrics, 127, 1034-1042.

Caballero, A., \& Connell, J. E. (2010). Evaluation of the effects of social cue cards for preschool age children with autism spectrum disorders (ASD). Journal of Behavior Assessment and Intervention in Children, 1, 25-42.

Camilli, G., \& Barnett, W. S. (2010). Meta-analysis of the effects of early education interventions on cognitive and social development. The Teachers College Record, 112, 579-620.

Carter, A. S., Davis, N. O., Klin, A., \& Volkmar, F. R. (2005). Social development in autism. Handbook of Autism and Pervasive Developmental Disorders, 1, 312-334.

Chan, J. M., \& O'Reilly, M. F. (2008). A Social Stories ${ }^{\mathrm{TM}}$ intervention package for students with autism in inclusive classroom settings. Journal of Applied Behavior Analysis, 41, 405-409.

Charman, T., Taylor, E., Drew, A., Cockerill, H., Brown, J.-A., \& Baird, G. (2005). Outcome at 7 years of children diagnosed with autism at age 2: Predictive validity of assessments conducted at 2 and 3 years of age and pattern of symptom change over time. Journal of Child Psychology and Psychiatry, and Allied Disciplines, 46, 500-513.

Cho Blair, K.-S., Umbreit, J., Dunlap, G., \& Jung, G. (2007). Promoting inclusion and peer participation through assessment-based intervention. Topics in Early Childhood Special Education, 27, 134-147.

Cihak, D. F., Smith, C. C., Cornett, A., \& Coleman, M. B. (2012). The use of video modeling with the picture exchange communication system to increase independent communicative initiations in preschoolers with autism and developmental Delays. Focus on Autism and Other Developmental Disabilities, 27, 3-11.

Crosland, K., \& Dunlap, G. (2012). Effective strategies for the inclusion of children with autism in general education classrooms. Behavior Modification, 36, 251-269.

Deitchman, C., Reeve, S., Reeve, K., \& Progar, P. (2010). Incorporating video feedback into self-management training to promote generalization of social initiations by children with autism. Education and Treatment of Children, 33, 375-388.

Dunn, L. M., Dunn, D. M., \& Assessments, P. (2007). PPVT-4: Peabody picture vocabulary test. Minneapolis: Pearson Assessments.

Ferraioli, S., \& Harris, S. (2011). Teaching joint attention to children with autism through a sibling mediated behavioral intervention. Behavioral Interventions, 2, 261-281.

Flippin, M., Reszka, S., \& Watson, L. R. (2010). Effectiveness of the Picture Exchange Communication System (PECS) on communication and speech for children with autism spectrum disorders: a metaanalysis. American Journal of Speech-Language Pathology, 19, 178-195.

Fombonne, E. (2003). The prevalence of autism. JAMA, the Journal of the American Medical Association, 289, 87-89.

Ganz, J. B., \& Flores, M. M. (2008). Effects of the use of visual strategies in play groups for children with autism spectrum disorders and their peers. Journal of Autism and Developmental Disorders, 38, 926-940.

Garrick, Duhaney, L. M., \& Salend, S. J. (2000). Parental perceptions of inclusive educational placements. Remedial and Special Education, $21,121-128$.

Gast, D. L., \& Ledford, J. (Eds.). (2010). Single-subject research methodology in behavioral sciences. New York: Routledge.

Goldstein, H., Lackey, K., \& Schneider, N. (2014). A new framework for systematic reviews: Application to social skills for preschoolers with autism. Exceptional Children, 80, 262-286.

Gray, C. A., \& Garand, J. D. (1993). Social stories: Improving responses of students with autism with accurate social information. Focus on Autistic Behavior, 8, 1-10.

Guralnick, M. J., Connor, R. T., Hammond, M., Gottman, J. M., \& Kinnish, K. (1996). Immediate effects of mainstreamed settings on the social interactions and social integration of preschool children. American Journal of Mental Retardation: AJMR, 100, 359-377. 
Harrower, J. K., \& Dunlap, G. (2001). Including children with autism in general education classrooms a review of effective strategies. Behavior Modification, 25, 762-784.

Hine, J., \& Wolery, M. (2006). Using point-of-view video modeling to teach play to preschoolers with autism. Topics in Early Childhood Special Education, 26, 83-93.

Horner, R. H., Carr, E. G., Halle, J., McGee, G., Odom, S., \& Wolery, M. (2005). The use of single-subject research to identify evidence-based practice in special education. Exceptional Children, 71, 165-179.

Hurley, J. J. (2012). Social validity assessment in social competence interventions for preschool children: a review. Topics in Early Childhood Special Education, 32, 164-174.

Hus, V., \& Lord, C. (2013). Effects of child characteristics on the autism diagnostic interview-revised: Implications for use of scores as a measure of ASD severity. Journal of Autism and Developmental Disorders, 43, 371-381.

IDEA (2004). Individuals With Disabilities Education Improvement Act, 20 U.S.C. $\$ 300.34$

Jones, E. A., Feeley, K. M., \& Takacs, J. (2007). Teaching spontaneous responses to young children with autism. Journal of Applied Behavior Analysis, 40, 565-570.

Jung, S., Sainato, D. M., \& Davis, C. A. (2008). Using high-probability request sequences to increase social interactions in young children with autism. Journal of Early Intervention, 30, 163-187.

Kern, P., \& Aldridge, D. (2006). Using embedded music therapy interventions to support outdoor play of young children with autism in an inclusive community-based child care program. Journal of Music Therapy, 43, 270-294.

Killoran, I., Woronko, D., \& Zaretsky, H. (2013). Exploring preservice teachers' attitudes towards inclusion. International Journal of Inclusive Education, 18, 427-442.

Koegel, R. L., Vernon, T. W., \& Koegel, L. K. (2009). Improving social initiations in young children with autism using reinforcers with embedded social interactions. Journal of Autism and Developmental Disorders, 39, 1240-1251.

Koegel, L. K., Kuriakose, S., Singh, A. K., \& Koegel, R. L. (2012). Improving generalization of peer socialization gains in inclusive school settings using initiations training. Behavior Modification, 36, 361-377.

Kohler, F. W., Greteman, C., Raschke, D., \& Highnam, C. (2007). Using a buddy skills package to increase the social interactions between a preschooler with autism and her peers. Topics in Early Childhood Special Education, 27, 155-163.

Kuppens, S., \& Onghena, P. (2012). Sequential meta-analysis to determine the sufficiency of cumulative knowledge: the case of early intensive behavioral intervention for children with autism spectrum disorders. Research in Autism Spectrum Disorders, 6, 168-176.

Leaf, J. B., Taubman, M., Bloomfield, S., Palos-Rafuse, L., Leaf, R., McEachin, J., et al. (2009). Increasing social skills and pro-social behavior for three children diagnosed with autism through the use of a teaching package. Research in Autism Spectrum Disorders, 3, 275-289.

Leaf, J. B., Oppenheim-Leaf, M. L., Call, N. A., Sheldon, J. B., Sherman, J. A., Taubman, M., et al. (2012). Comparing the teaching interaction procedure to social stories for people with autism. Journal of Applied Behavior Analysis, 45, 281-298.

Liber, D. B., Frea, W. D., \& Symon, J. B. G. (2008). Using time-delay to improve social play skills with peers for children with autism. Journal of Autism and Developmental Disorders, 38, 312-323.

Licciardello, C. C., Harchik, A. E., \& Luiselli, J. K. (2008). Social skills intervention for children with autism during interactive play at a public elementary school. Education and Treatment of Children, 31, 27-37.

Macduff, G. S., Krantz, P. J., \& Mcclannahan, L. E. (1993). Teaching children with autism to use photographic activity schedules: Maintenance and generalization of complex response chains. Journal of Applied Behavior Analysis, 1, 89-97.

Maione, L., \& Mirenda, P. (2006). Effects of video modeling and video feedback on peer-directed social language skills of a child with autism. Journal of Positive Behavior Interventions, 8 , 106-118.

Marzullo-Kerth, D., Reeve, S. A., Reeve, K. F., \& Townsend, D. B. (2011). Using multiple-exemplar training to teach a generalized repertoire of sharing to children with autism. Journal of Applied Behavior Analysis, 44, 279-294.

McClelland, M. M., \& Morrison, F. J. (2003). The emergence of learningrelated social skills in preschool children. Early Childhood Research Quarterly, 18, 206-224.

Mesibov, G. B., \& Shea, V. (1996). Full inclusion and students with autism. Journal of Autism and Developmental Disorders, 26, 337-346.

Morrier, M. J., Hess, K. L., \& Heflin, L. J. (2010). Teacher training for implementation of teaching strategies for students with autism spectrum disorders. Teacher Education and Special Education: The Journal of the Teacher Education Division of the Council for Exceptional Children, 34, 119-132.

Nelson, C., \& McDonnell, A. (2007). Keys to play: a strategy to increase the social interactions of young children with autism and their typically developing peers. Education and Training in Developmental Disabilities, 42, 165-181.

Newschaffer, C. J., Croen, L. A., Daniels, J., Giarelli, E., Grether, J. K., Levy, S. E., et al. (2007). The epidemiology of autism spectrum disorders*. Annual Review Public Health, 28, 235-258.

Odom, S. L. (2000). Preschool inclusion what we know and where we go from here. Topics in Early Childhood Special Education, 20, 20-27.

Odom, S. L., Brown, W. H., Frey, T., Karasu, N., Smith-Canter, L. L., \& Strain, P. S. (2003). Evidence-based practices for young children with autism contributions for single-subject design research. Focus on Autism and Other Developmental Disabilities, 18, 166-175.

Odom, S. L., Zercher, C., Li, S., Marquart, J. M., Sandall, S., \& Brown, W. H. (2006). Social acceptance and rejection of preschool children with disabilities: a mixed-method analysis. Journal of Educational Psychology, 98, 807-823.

Odom, S. L., Buysse, V., \& Soukakou, E. (2012). Inclusion for young children with disabilities: a quarter century of research perspectives. Journal of Early Intervention, 33, 344-356.

Parker, R. I., Vannest, K. J., \& Davis, J. L. (2011). Effect size in singlecase research: a review of nine nonoverlap techniques. Behavior Modification, 35(4), 303-322.

Pierce-Jordan, S., \& Lifter, K. (2005). Interaction of social and play behaviors in preschoolers with and without pervasive developmental disorder. Topics in Early Childhood Special Education, 25, 34-47.

Powell, D., Dunlap, G., \& Fox, L. (2006). Prevention and intervention for the challenging behaviors of toddlers and preschoolers. Infants \& Young Children, 19, 25-35.

Ravet, J. (2011). Inclusive Inclusive/exclusive? Contradictory perspectives on autism and inclusion: the case for an integrative position. International Journal of Inclusive Education, 15, 667-682.

Reichow, B. (2011). Development, procedures, and application of the evaluative method for determining evidence-based practices in autism. Evidence-based practices and treatments for children with autism (pp. 25-39). Springer US.

Reichow, B. (2012). Overview of meta-analyses on early intensive behavioral intervention for young children with autism spectrum disorders. Journal of autism and developmental disorders, 42(4), 512520.

Reichow, B., Volkmar, F. R., \& Cicchetti, D. V. (2008). Development of the evaluative method for evaluating and determining evidencebased practices in autism. Journal of Autism and Developmental Disorders, 38, 1311-1319.

Rispoli, M. J., Davis, H. S., Goodwyn, F. D., Camargo, S., Goodwyn, F. D., \& Camargo, S. (2013). Behavior Interventions The use of trialbased functional disabilities.

Schreibman, L. (2000). Intensive behavioral/psychoeducational treatments for autism: Research needs and future directions. Journal of autism and developmental disorders, 30(5), 373-378. 
Stanton-Chapman, T. L., Denning, C. B., \& Jamison, K. R. (2012). Communication skill building in young children with and without disabilities in a preschool classroom. The Journal of Special Education, 46, 78-93.

Stella, J., Mundy, P., \& Tuchman, R. (1999). Social and nonsocial factors in the childhood autism rating scale. Journal of Autism and Developmental Disorders, 29, 307-317.

Thomas, B., Lafasakis, M., \& Sturmey, P. (2010). The effects of prompting, fading, and differential reinforcement on vocal mands in non-verbal preschool children with autism spectrum disorders. Behavioral Interventions, 168, 157-168.

Tiger, J. H., Hanley, G. P., \& Heal, N. A. (2006). The effectiveness of and preschoolers' preferences for variations of multiple-schedule arrangements. Journal of Applied Behavior Analysis, 39, 475-488.

Virues-Ortega, J. (2009). Applied behavior analytic intervention for autism in early childhood: Meta-analysis, meta-regression, and doseresponse meta-analysis of multiple outcomes. Clinical Psychology Review, 30, 387-395.

Von der Embse, N., Brown, A., \& Fortain, J. (2011). Facilitating inclusion by reducing problem behaviors for students with autism spectrum disorders. Intervention in School and Clinic, 47, 22-30.
Wang, P., \& Spillane, A. (2009). Evidence-based social skills interventions for children with autism: a meta-analysis. Education and Training in Developmental Disabilities, 44, 318-342.

Wetherby, A. M., Watt, N., Morgan, L., \& Shumway, S. (2007). Social communication profiles of children with autism spectrum disorders late in the second year of life. Journal of Autism and Developmental Disorders, 37, 960-975.

Wichnick, A., Vener, S., Pyrtek, M., \& Poulson, C. (2010). The effect of a script-fading procedure on responses to peer initiations among young children with autism. Research in Autism Spectrum Disorders, 4, 290-299.

Wiig, E. H., Secord, W. A., \& Semel, E. (2004). Clinical evaluation of language fundamentals-Preschool, second edition (CELF Preschool-2). Toronto: The Psychological Corporation/A Harcourt Assessment Company.

Williams White, S., Keonig, K., \& Scahill, L. (2007). Social skills development in children with autism spectrum disorders: a review of the intervention research. Journal of Autism and Developmental Disorders, 37, 1858-1868.

Woods, J., \& Poulson, C. (2006). The use of scripts to increase the verbal initiations of children with developmental disabilities to typically developing peers. Education and Treatment of Children, 29, 437-454. 